\title{
Effect of root curvature on post length in the restoration of endodontically treated premolars
}

Zillich R, Yaman P. Effect of root curvature on post length in the restoration of endodontically treated premolars. Endod Dent Traumatol 1985; 1: 135-137.

Abstract - Two hundred and eighteen bi-rooted maxillary premolars were examined radiographically to determine the length from the apex at which root curvature occurred. The information may serve as a guide in determining post preparation length. The results of the study indicated that the lingual root was slightly straighter than the buccal root. The curvature of the root was on the average $6.47 \mathrm{~mm}$ from the apex on the buccal root and $5.48 \mathrm{~mm}$ from the apex on the lingual root.

\section{Richard Zillich ${ }^{1}$ and Peter Yaman ${ }^{2}$}

'University of Michigan, School of Dentistry, Department of Endodontics, and ${ }^{2}$ Department of Operative Dentistry, Ann Arbor, MI, USA

Key words: endodontic treatment, post length, root anatomy, human premolars.

Richard Zillich, D.D.S., M.S., Associate Professor, Department of Endodontics, School of Dentistry, University of Michigan, Ann Arbor, MI 48109, USA. Accepted for publication 20 March 1985.
Numerous papers and articles have been presented and written on post preparations for restoring endodontically treated teeth. Colley et al. (1) and Caputo \& Standlee (2) are two of the classic papers on retention and stress distribution of posts. Other authors have suggested various diameters, taper, surface configurations and lengths for posts. Tilk et al. (3) and Shillingburg \& Kessler (4) have reported on natural root diameters and have suggested dowel sizes. Others suggest post lengths equal to or $1 \frac{1}{2}$ times that of the crown, $50 \%$ to $80 \%$ of the root length, or $50 \%$ of the depth of the tooth's root in alveolar bone. Some articles have suggested leaving 3-5 $\mathrm{mm}$ of root canal filling in place to maintain an apical seal. Zillich \& Corcoran (5) have suggested that various post length recommendations do not always coincide with natural tooth dimensions.

The purpose of this paper is to compile and report data on the effect of natural root curvature on post preparation depth.

\section{Material and methods}

Two-hundred-twenty-eight human maxillary premolars were selected from the University of Michigan School of Dentistry reserves. All premolars selected had to have 2 roots.

Each tooth was radiographed from a proximal (mesio-distal) vantage using standard techniques with a cone-film distance of $2.5 \mathrm{~mm}$. Root measurements were taken and recorded (Fig. 1). The teeth were then sectioned in a mesiodistal plane, thus separating the tooth into a buccal and a lingual root (Fig. 2). The 2 roots were then individually

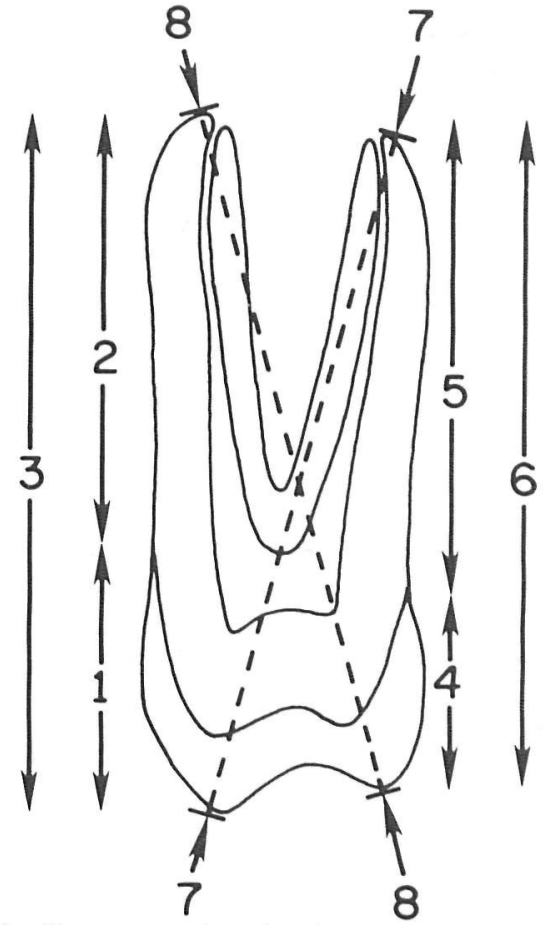

Fig. 1. Maxillary premolar showing measurements taken and recorded.

radiographed from a bucco-lingual vantage using the same standard techniques as used for the proximal views.

The radiographs were placed on a shielded viewing box in a darkened room for maximum contrast. They were then analyzed using the Schneider (6) method (Fig. 3). First, a line was drawn which 


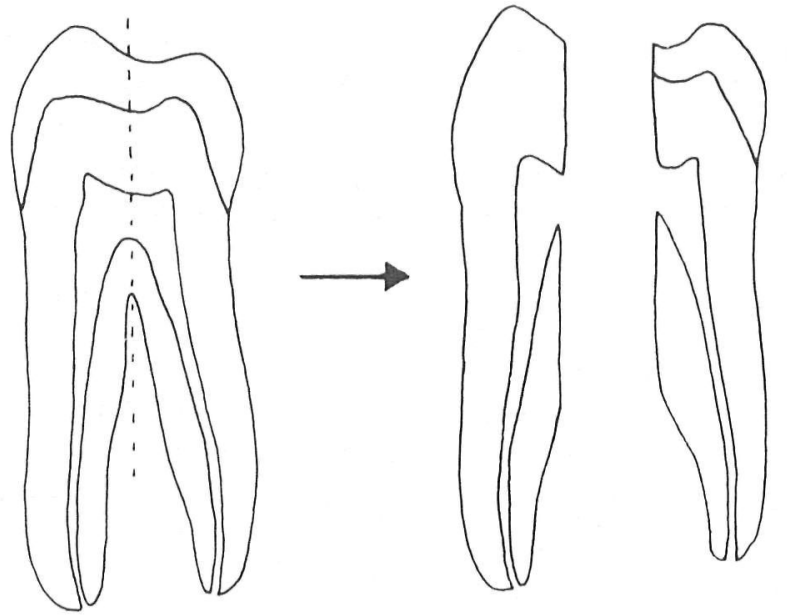

Fig. 2. Premolar diagram showing mesio-distal sectioning to obtain 2 separate roots.
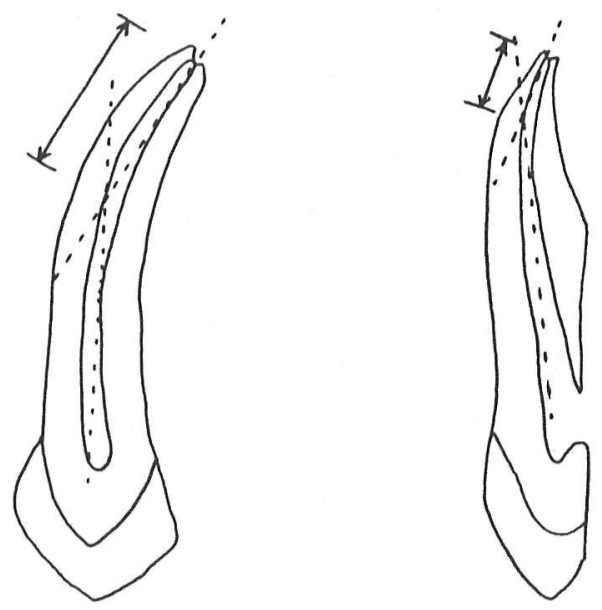

Fig. 3. The distance from the apex measured, recorded and means calculated per the Schncider method.

was parallel to the long axis of the canal. A second line was scribed from the apical foramen to intersect with the first line at the point at which the canal began to leave the long axis of the tooth. The straight line distance from the apical foramen to the intersection of the two lines was then measured for both radiographic views to the nearest $0.1 \mathrm{~mm}$. Depth was recorded as length from the apex because in clinical situations this landmark is easier to identify on a radiograph than a cusp tip or the cementoenamel junction. The radiographic distortion was minimized by using a constant KVP, ma and exposure time, as well as a constant source-object and object-film distance.

\section{Results}

Ten teeth were discarded due to calcification, previous root canal filling, or open apex, thus leaving

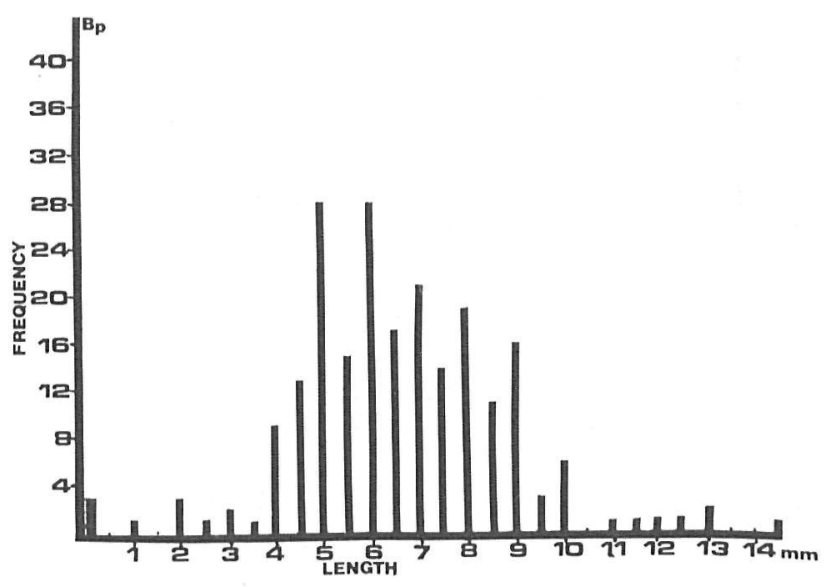

Fig. 4. Buccal root, frequency distribution of lengths from the apex taken from the proximal vantage. The mean length from the apex was $6.36 \mathrm{~mm}$.

218 teeth for examination. The average length of the teeth was $20.65 \mathrm{~mm}$.

The average distance from the apex for the buccal root straight line depth was $6.36 \mathrm{~mm}$ and $6.57 \mathrm{~mm}$ in the mesio-distal and bucco-lingual projection, respectively. The corresponding means for the lingual root were $5.58 \mathrm{~mm}$ and $6.09 \mathrm{~mm}$ (Fig. 4-7). When the mean was calculated by using the view in which the root curvature was farthest from the apex, the buccal and lingual measurements were $7.22 \mathrm{~mm}$ and $6.52 \mathrm{~mm}$ respectively. None of the roots was straight to the apex when viewed from both projections.

\section{Discussion}

The average length of the teeth as observed in the present study was within $1 \mathrm{~mm}$ of the average

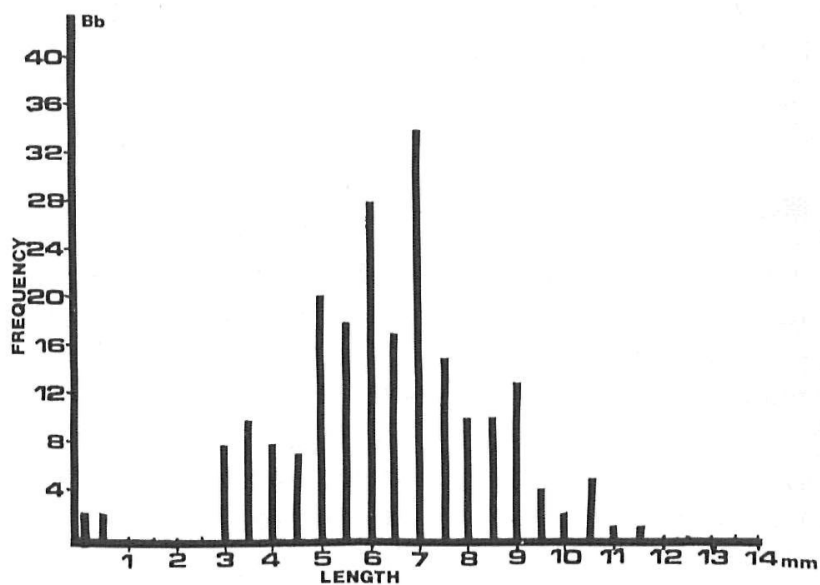

Fig. 5. Buccal root, frequency distribution of lengths from the apex taken from the buccal vantage. The mean length from the apex was $6.57 \mathrm{~mm}$. 


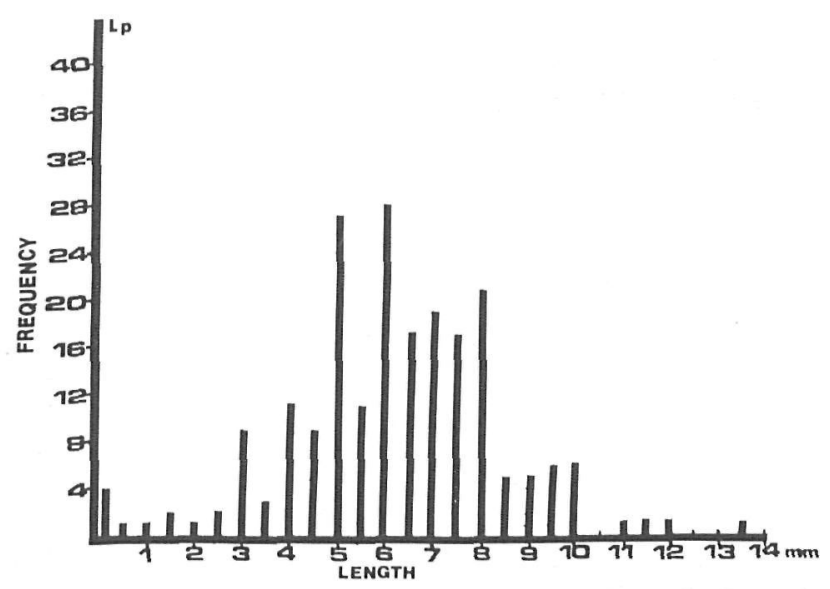

Fig. 6. Lingual root, frequency distribution of lengths from the apex taken from the proximal vantage. The mean length from the apex was $5.58 \mathrm{~mm}$.

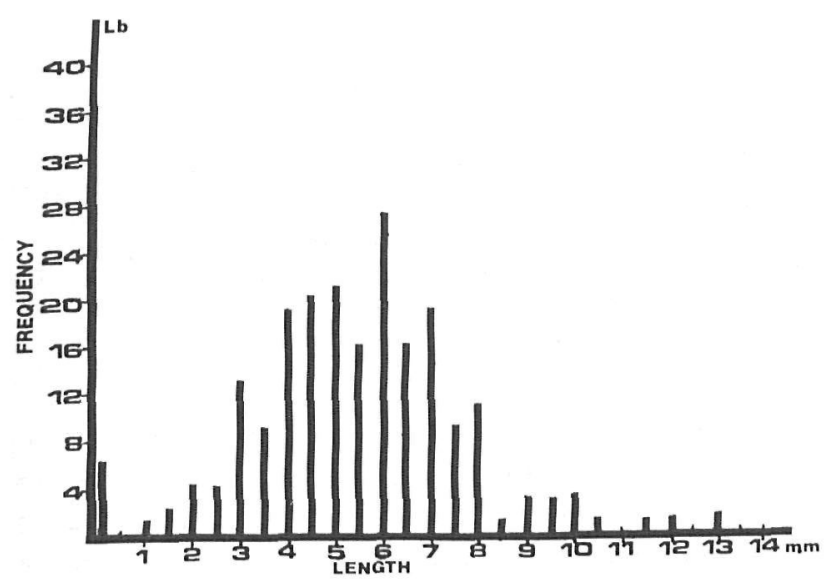

Fig. 7. Lingual root, frequency distribution of lengths from the apex taken from the buccal vantage. The mean length from the apex was $6.09 \mathrm{~mm}$.

lengths given by Black (7) and Weine (8). It is within $1.65 \mathrm{~mm}$ of the average tooth length given by Wheeler (9) and Bjorndahl et al. (10).

As reported earlier (5) a post length of $1 / 2$ the root length is the least likely to affect the apical seal on premolar teeth. This was calculated at a $5 \mathrm{~mm}$ depth from the apex, assuming that the endodontic treatment would be in the ideal range. The results of this study show that the post preparation should be no closer to the apex than $6 \mathrm{~mm}$.
The data support the clinical impression that the lingual root of premolars is the straightest of the 2 roots. This was only true, however, by less than an average of $1 \mathrm{~mm}$. Some roots were straight to the apex on one view, but none was straight to the apex on both views. This should prompt the practitioner to be wary of the clinically straight root.

Root curvature and its effect on the length of a post preparation have been overlooked in previous studies. The factor of curvature plays a very important role in both endodontic and restorative procedures. Many failures in treatment may occur because the post preparation is too long for the natural dimensions of the tooth. This study gives data on only one type of tooth in the dentition, but it clearly indicates that the post space should not be made any longer than absolutely necessary.

\section{Summary}

Two-hundred-eighteen bi-rooted maxillary premolars were examined to determine the length from the apex at which root curvature occurred. The data showed that, on average, the curvature of the root was $6.47 \mathrm{~mm}$ from the apex on the buccal root and 5.84 from the apex on the lingual root.

\section{References}

1. Colley it, Hampson El, Lehman ML. Retention of post crowns: An assessment of the relative efficiency of posts of difficult shapes and sizes. Br Dent $y$ 1968; 124; 65.

2. Caputo $\Lambda \Lambda$, Standlee JP. Pins and posts - why, when and how. Dent Clin N Am 1976; 20: 299.

3. Tilk MA, Lommei. TJ, Gerstein H. A study of mandibular and maxillary root widths to determine dowel size. $J$ Endodont 1979; 5: 79.

4. Shillingburg HT, Kessler JC. Restoration of the endodontically treated tooth, 1st ed. Chicago: Quintessence Publishing Co., 1982.

5. Zillich RM, Corcoran JF. Maximum post lengths in endodontically treated tecth. F Prosth Dent 1984; 52: 489.

6. Schnemer SW. A comparison of canal preparations in straight and curved root canals. Oral Surg 1971; 32: 271

7. BLAck GV. Descriptive anatomy of the human teeth, 4 th ed. Philadelphia: S. S. White, 1897 (from Bjorndahl [10]).

8. Weine FS. Endodontic therapy, 3rd cd. St. Louis: C. V. Mosby Co., 1982; ix +692 pp.

9. Wheeler C. Dental anatomy, physiology and occlusion, 5 th ed. Philadelphia: W. B. Saunders, 1974; xiii +520 pp.

10. Bjorndahl AM, Henderson WG, Skidmore AE, Kelllner FH. Anatomic measurements of human teeth extracted from males between the ages of 17 and 21 years. Oral Surg 1974; 38: 791 . 
This document is a scanned copy of a printed document. No warranty is given about the accuracy of the copy. Users should refer to the original published version of the material. 